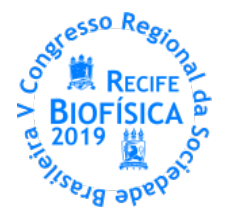

\title{
SOLVENTES VERDES? TALVEZ NÃO: UM ESTUDO SOBRE A INFLUÊNCIA DOS LÍQUIDOS IÔNICOS IMIDAZÓLICOS EM BICAMADAS LIPÍDICAS
}

\author{
Maria Isabel dos Santos Cavalcanti ${ }^{1 *}$, Manuela Correia Dionísio ${ }^{1}$, Júlio César Avelino da Silva ${ }^{1}$, Juliana Pereira de \\ Aguiar ${ }^{1}$, Cláudio Gabriel Rodrigues ${ }^{1}$, Dijanah Cota Machado ${ }^{1}$ \\ ${ }^{1}$ Laboratório de Biofísica das Membranas e Células-Tronco - Dr. Oleg Krasilnikov, Departamento de Biofísica e Radiobiologia, Centro de \\ Biociências, Universidade Federal de Pernambuco \\ *cavalcanti.isa21@gmail.com
}

\section{INTRODUÇÃO}

Líquidos iônicos (Lls) são sais orgânicos com ponto de fusão abaixo de $100{ }^{\circ} \mathrm{C}$. São formados a partir da combinação de um cátion orgânico e um ânion inorgânico ou por um ânion orgânico e um cátion inorgânico, esse baixo nível de simetria entre seus constituintes reduz a energia da estrutura cristalina, e consequentemente, torna mais baixo o seu ponto de fusão (MACFARLANE \& SEDDON, 2007; CLOUGH et al., 2015).

O pioneiro na síntese de Lls foi Paul Walden que, em 1914, sintetizou e descreveu as propriedades físico-químicas do nitrato de etilamônio (PLECHKOVA \& SEDDON, 2008). Desde então diversos pesquisadores trabalham na síntese de LIs com diferentes combinações de cátions e ânions (HALLET \& WELTON, 2011). Inicialmente, os LIs foram desenvolvidos para serem utilizados como solução eletrolítica de baterias (ARMAND et al., 2009), entretanto, devido às suas propriedades físico-químicas peculiares e a habilidade de dissolver vários complexos de metais foram ganhando espaço e potencial aplicação em processos industriais e novas tecnologias químicas (VEKARIYA, 2017), como em reações orgânicas e catalíticas; na síntese de novos materiais, solventes em processos de extração (HALLET \& WELTON, 2011), na dessulfuração de combustíveis (BÖSMANN et al., 2001) e como lubrificantes (LIU et al., 2002), entre outras.

Por apresentarem importantes propriedades como baixa volatilidade, baixa inflamabilidade, baixa pressão de vapor, alta estabilidade térmica, alta condutividade iônica, alta capacidade de hidratação e possuem capacidade de dissolver uma grande variedade de solutos (BATES et al., 2002 ARMAND et al., 2009), essa classe de solventes é considerada como sendo um "solvente verde", por, supostamente, não promover danos à natureza (PLECHKOVA \& SEDDON, 2008).

Devido a essas características vem despertando a curiosidade da comunidade acadêmica e industrial (NAUSHAD et al., 2012). No âmbito biológico, os Lls têm recebido especial atenção no desenvolvimento de sistemas musculares artificiais. Além disso, uma recente aplicação dos Lls é no desenvolvimento de biossensores estocásticos. Neste caso, esses sais orgânicos são utilizados como solução banhante eletrolítica de nanoporos proteicos em plataformas de sensoriamento para melhorar a resolução e sensibilidade da técnica (LIU et al., 2010; MODI et al., 2011).

Entretanto, sua baixa volatilidade impede que entre em contato com seres vivos por via aérea, e por conta disso, é considerado um solvente de uso seguro, ou seja, de baixa toxicidade. Contudo isso não impossibilita de tal composto estar presente em outros meios, por exemplo aquático, e causar algum transtorno ao ser vivo. A influência destes líquidos sobre plantas, bactérias, fungos e animais ainda não é clara, e merece maior atenção (CVJETKO, et al, 2012). Estudos de ecotoxicidade com Lls vêm relatando que eles não são tão inofensivos assim (STEPNOWSKI et al., 2004; ZHAO et al. 2007; RUOKONEN et al., 2016) e que, provavelmente, seu local de ação seja a nível intracelular, portanto, eles precisam atravessar a membrana plasmática. Desta maneira, para avaliar o mecanismo de toxicidade de Lls imidazólicos, este trabalho objetiva analisar a influência do cloreto de 1-etil-3-metil imidazólio (EMIMCl) e do cloreto de 1-decil-3-metil imidazólio (DMIMCl) em membranas artificiais planas, uma vez que este sistema, possibilita maior controle da composição lipídica.

\section{MATERIAIS E MÉTODOS}

Para a confecção da bicamada lipídica plana foi utilizada a técnica de Montal \& Mueller (1972), usando o lipídeo sintético diftanoilfosfatidilcolina (Avanti Polar Lipids) 2\% (p/v) em hexano (Merck). Esta técnica consiste basicamente na formação de uma bicamada lipídica por aposição de dois filmes monomoleculares de lipídeo em um orifício ( 100 $\mu \mathrm{m}$ diâmetro) de uma partição de Teflon ${ }^{\circledR}$ que separa dois compartimentos idênticos de uma câmara experimental de Teflon, contendo solução eletrolítica. Antes da formação da bicamada, o orifício foi pré-tratado com uma solução de $1 \%(\mathrm{v} / \mathrm{v})$ de hexadecano em hexano (Merck). Nos dois compartimentos da câmara foi adicionada solução eletrolítica composta por $100 \mathrm{mM}$ de $\mathrm{KCl}, 5 \mathrm{mM}$ de tampão Tris-ácido cítrico (pH 7,5). Os LIs testados foram o cloreto de 1-etil-3-metil imidazólio (EMIMCl) e cloreto de 1-decil-3-metil imidazólio (DMIMCl), ambos têm em comum o cátion orgânico imidazólio, diferindo entre si quanto ao comprimento da cadeia carbônica, o EMIMCl tem 2 carbonos e o DMIMCl tem 10 carbonos na sua cadeia carbônica, e formam sal com ânion cloreto. Após a adição de alíquotas do líquido iônico na solução banhante, foram aplicados potenciais de $\pm 20 \mathrm{a} \pm 100 \mathrm{mV}$ (em incrementos de $20 \mathrm{mV}$ ). Todos os experimentos foram realizados usando um amplificador Axopatch 200B (Axon Instruments) em modo de fixação de voltagem. Potencial de membrana foi mantido usando eletrodos prata/cloreto de prata $(\mathrm{Ag} / \mathrm{AgCl})$ em pontes salinas de $3 \%$ de Ágar em $3 \mathrm{M} \mathrm{KCl}$. As correntes iônicas foram filtradas por um filtro passa-baixa Butterworth (model 9002; Frequency Devices, Haverhill, MA) a 15 $\mathrm{kHz}$ e diretamente salvas na memória de um computador com uma taxa de amostragem de $250 \mathrm{kHz}$. Todos os experimentos foram realizados em temperatura ambiente de $23 \pm 2{ }^{\circ} \mathrm{C}$. 


\section{RESULTADOS E DISCUSSÃO}

$\mathrm{Na}$ Figura 1 tem-se o resultado da adição do EMIMCl, na concentração final de $500 \mu \mathrm{M}$, na solução eletrolítica que banha a bicamada lipídica composta pelo lipídeo neutro diftanoilfosfatidilcolina. Podem ser observadas flutuações na corrente iônica da membrana, sugestivo de uma provável formação de poros na bicamada lipídica, evidenciado pelos saltos discretizados.

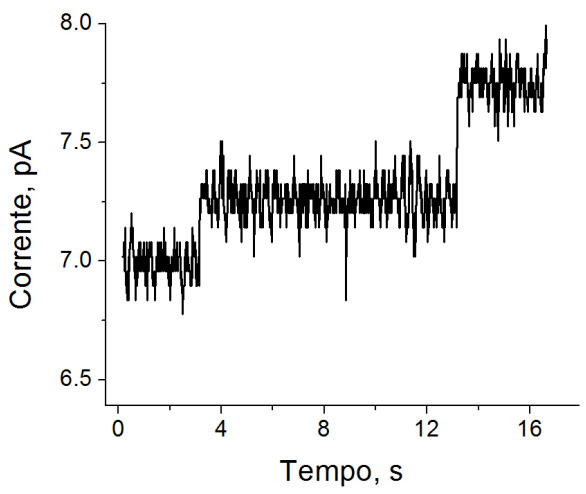

Figura 1. Estabilidade da bicamada lipídica plana na presença de EMIMCI. A adição de EMIMCI na solução banhante da bicamada, na concentração final de $500 \mu \mathrm{M}$, altera a estabilidade da membrana evidenciada pela formação de saltos discretizados na corrente iônica. Voltagem aplicada de $100 \mathrm{mV}$. Solução banhante composta por KCl 100 $\mathrm{mM}$, TRIS $5 \mathrm{mM}$ e pH 7,5 ajustado com ácido cítrico.

Igualmente ao EMIMCl, a adição de DMIMCI na solução banhante, na concentração final de $100 \mu \mathrm{M}$, alterou a estabilidade da bicamada com a formação de um poro na membrana lipídica com corrente iônica de cerca de 4 pA (Figura 2).

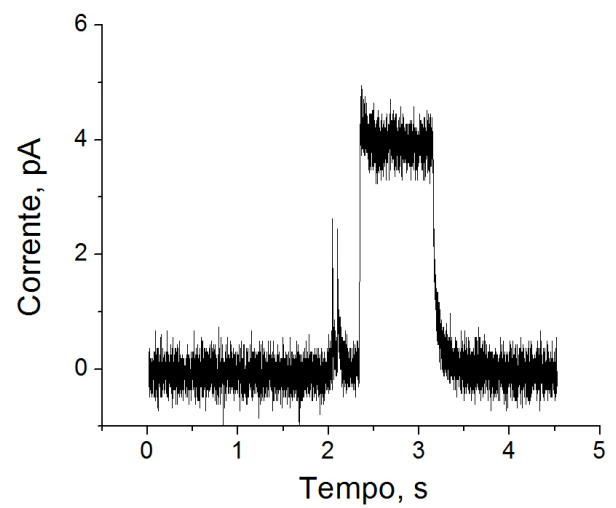

Figura 2. Estabilidade da bicamada lipídica plana na presença de DMIMCl. A adição de DMIMCl na solução banhante, na concentração final de $100 \mu \mathrm{M}$, induziu a formação de um poro na membrana lipídica. Voltagem aplicada de $40 \mathrm{mV}$. Solução banhante composta por $\mathrm{KCl} 100 \mathrm{mM}$, TRIS $5 \mathrm{mM}$ e pH 7,5 ajustado com ácido cítrico.

Nota-se que tanto o EMIMCl quanto o DMIMCl alteraram a estabilidade da membrana, gerando flutuacões discretizadas na corrente iônica similar ao comportamento eletrofisiológico de um poro iônico. Provavelmente, esse efeito ocorre devido à entrada da cadeia alquil do cátion imidazólico na região hidrofóbica da bicamada lipídica promovendo uma perturbação dos ácidos graxos da membrana gerando uma via condutiva a íons (JING et al., 2016; BENEDETTO, 2017).

A adição de uma concentração maior de DMIMCl (1 mM) na solução banhante ocasionou a ruptura da bicamada lipídica (dado não mostrado). Estudo desenvolvido por Wang e cols. (2015) mostrou que a estrutura dos Lls permite a formação de micelas, e quanto maior o comprimento da sua cadeia alquílica, maior a capacidade da formação de micelas. Isso pode resultar na formação de "buracos" nas bicamadas e levar ao seu rompimento, caracterizando um mecanismo citotóxico descrito na literatura por Yoo e cols. (2016), reforçando a hipótese de que os líquidos iônicos são citotóxicos, sendo prejudicial aos seres vivos e ao meio ambiente.

Os dados obtidos neste trabalho evidenciam a necessidade de reavaliação das condições de manuseio e descarte dos Lls imidazólicos e podem auxiliar em um melhor entendimento dos mecanismos envolvidos na toxicidade de líquidos iônicos em seres vivos.

\section{CONCLUSÕES}

Os líquidos iônicos imidazólicos EMIMCl e DMIMCl alteram a estabilidade da membrana lipídica com efeito dose-dependente. Os resultados obtidos neste estudo fornecem base experimental para futuras investigações a respeito do mecanismo de ação dos líquidos iônicos em células e sua toxicidade.

\section{REFERÊNCIAS}

ARMAND, M. et al. Ionic-liquid materials for the electrochemical challenges of the future. Nature Materials, v. 8, p. 621, 2009.

BATES, E.D. et al. $\mathrm{CO}_{2}$ capture by a task-specific ionic liquid. Journal of the American Chemical Society, v. 124, p. 926-927, 2002.

BENEDETTO, A. Room-temperature ionic liquids meet biomembranes: the state-of-the-art. Biophysical Reviews, v. 9, p. 309-320, 2017.

BÖSMANN, A. et al. Deep desulfurization of diesel fuel by extraction with ionic liquids. Chemical Communications, v. 23, p. 2494-2495, 2001.

CVJETKO, M. et al. Cytotoxic effects of imidazolium ionic liquids on fish and human cell lines. Arhiv za higijenu rada $i$ toksikologiju, v. 63, p. 15-19, 2012.

HALLETT, J.P.; WELTON, T. Room-temperature ionic liquids: solvents for synthesis and catalysis. 2. Chemical Reviews, v. 111, p. 3508-3576, 2011.

JING, B. et al. Interaction of ionic liquids with a lipid bilayer: a biophysical study of ionic liquid cytotoxicity. The Journal of Physical Chemistry B, v. 120, p. 2781-2789, 2016.

LIU, W. et al. Tribological performance of room-temperature ionic liquids as lubricant. Tribology Letters, v. 13, p. 81-85, 2002.

LIU, A.; ZHAO, Q.; GUAN, X. Stochastic nanopore sensors for the detection of terrorist agents: current status and challenges. Analytica Chimica Acta, v. 675, p. 106-115, 2010.

MACFARLANE, D.R.; SEDDON, K.R. Ionic liquids progress on the fundamental issues. Australian Journal of Chemistry, v. 60 , p. 35, 2007.

MODI, N. et al. Probing the transport of ionic liquids in aqueous solution through nanopores. The Journal of Physical Chemistry Letters, v. 2, p. 2331-2336, 2011.

MONTAL, M.; MUELLER, P. Formation of bimolecular membranes from lipid monolayers and a study of their electrical properties. Proceedings of the National Academy of Sciences, v. 69, p. 35613566, 1972.

NAUSHAD, M. et al. Effect of ionic liquid on activity, stability, and structure of enzymes: a review. International Journal of Biological Macromolecules, v. 51, p. 555-560, 2012.

PLECHKOVA, N.V.; SEDDON, K.R. Applications of ionic liquids in the chemical industry. Chemical Society Reviews, v. 37, p. 123-150, 2008.

RUOKONEN, S. et al. Effect of ionic liquids on zebrafish (danio rerio) viability, behavior, and histology; correlation between toxicity and ionic liquid aggregation. Environmental Science \& Technology, v. 50, p. 7116-7125, 2016. 
STEPNOWSKI, P. et al. Evaluating the cytotoxicity of ionic liquids using human cell line HeLa. Human \& Experimental Toxicology, v. 23, p. 513-517, 2004.

VEKARIYA, R.L. A review of ionic liquids: applications towards catalytic organic transformations. Journal of Molecular Liquids, v. 227, p. 44-60, 2017.

WANG, D. et al. A Remarkably Simple Class of Imidazolium-Based Lipids and Their Biological Properties. Chemistry-A European Journal, v. 21, p. 15123-15126, 2015.

YOO, B. et al. Molecular mechanisms of ionic liquid cytotoxicity probed by an integrated experimental and computational approach. Scientific Reports, v. 6, p. 19889, 2016.

ZHAO, D.; LIAO, Y.; ZHANG, Z. Toxicity of ionic liquids. Clean-soil, air, water, v. 35, p. 42-48, 2007. 